\title{
PRECIPITABLE IODINE OF SERUM (SPI) IN DISORDERS OF THE LIVER ${ }^{1}$
}

\author{
By DAVID M. KYDD ANd EVELYN B. MAN \\ (From the Department of Internal Medicine, Yale University School of Medicine, New Haven, \\ Conn.)
}

(Submitted for publication March 19, 1951; accepted June 4, 1951)

Recently, high values of precipitable iodine of the serum (SPI) in certain instances of hepatitis and variable values in cirrhosis of the liver have been reported from this laboratory $(1,2)$. Inas- much as these sporadic high values in hepatitis were at variance with our usual findings, and because high, low and normal values have been found in cirrhosis, additional studies of patients with disorders of the liver have been conducted.

\section{MATERIALS AND METHODS}

Patients with obstructive jaundice, cirrhosis of the liver and infectious hepatitis were observed on the wards of the New Haven Hospital. All were in a post-absorptive state. None had had gall bladder dyes, diodrast, lipiodol or other substances known to give high artifactual values of SPI. None had had any mercurial diuretics within the period during which these substances may affect the determination of SPI (3). None had had any unusual contact with inorganic iodine (4). SPI, lipids, proteins, bilirubin, alkaline phosphatase and the percentage of bromsulphalein retention were determined by methods previously described $(2,5-7)$.

\section{RESULTS}

In obstructive jaundice six values of SPI obtained in five individuals were all within the established normal range (2) (Table I). In addition to considerable jaundice these patients had grossly disturbed liver function as measured by the high ratio of free to total cholesterol and other tests. In cirrhosis of the liver 31 values of SPI in 21 individuals varied from 1.0 to 8.8 gamma per cent (Table I). Of these values, however, only two are greater than occur in normal persons. A concentration of 8.0 gamma per cent, a value barely exceeding the normal 7.8 gamma per cent, was found in HD in whom a value of 6.6 gamma per cent had been found 16 months previously at a time

\footnotetext{
1 Aided by grants from the U. S. Public Health Service and the James Hudson Brown Memorial Fund of the Yale University School of Medicine.
}

when her clinical condition appeared to indicate a more decompensated cirrhosis than when the later result was obtained. A value of 8.8 gamma per cent was obtained in AS who had had symptoms of cirrhosis for only three months. A biopsy of the liver showed the typical histology associated with cirrhosis without evidence of other liver disease. Low values are more common. In fact, SPI may be as low as concentrations usually associated with hypothyroidism although other evidences of this disorder are absent. Despite the occurrence of these abnormal values, SPI is often normal in cirrhosis of varying severity.

In infectious hepatitis 18 values in nine patients varied from 3.4 to 11.5 gamma per cent (Table I). Serial observations of SPI during hepatitis show that early in the disease SPI is elevated but that as the disease continues, SPI falls to a normal value (Figure 1). All of the abnormal concentrations of SPI were obtained during the first four weeks of the illness. Subsequently, SPI remained normal despite the continued activity of the hepatitis as measured by the continued abnormalities of liver function, jaundice and often clinical condition of the patient. In M. D., for example, about two months before her death from hepatitis when $\mathbf{7 2}$ per cent of the serum cholesterol was not esterified and the other liver function tests were markedly deranged, SPI was 5.3 gamma per cent. However, at this time the disease had been present for more than four months. The highest SPI was obtained in RC who was examined 16 days after symptoms of the disease first appeared.

\section{DISCUSSION}

In cirrhosis of the liver, reduction in SPI is correlated with evidences of the severity of the disease, but not with any single functional test. Because of the variability of SPI within the normal range only abnormally low concentrations can be considered. All of these values are associated with 
PRECIPITABLE IODINE OF SERUM IN DISORDERS OF LIVER

TABLE I

$S P I$, lipids, and liver function tests in disorders of the liver

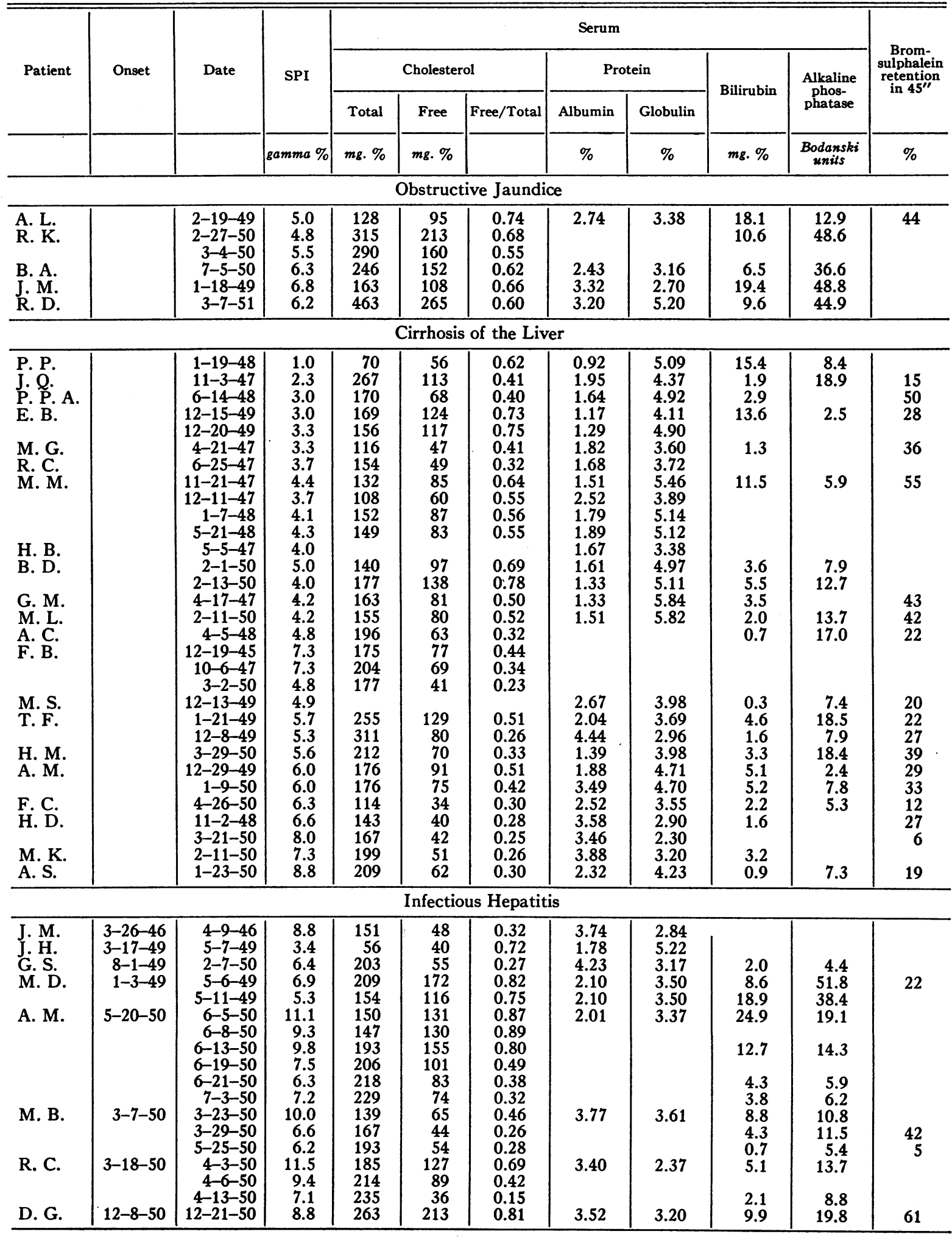


a high percentage of nonesterified cholesterol in the serum, a sensitive indication of liver damage (8). However, such lipid disturbances or alterations in the concentration of cholesterol are not always accompanied by reduction in SPI. Correlation with the other liver function tests is even less apparent. That the low values of SPI in cirrhosis might be related to the frequent occurrence of a decreased amount of albumin in the serum of patients with this disease has been suggested (1) inasmuch as the organic or thyroxine-like fraction of the total iodine of the serum is attached to the serum proteins $(9,10)$. However, if SPI be compared directly with the concentration of albumin no definite correlation is found. The lowest values of SPI are found in patients with diminished serum albumin, but SPI is often moderately, or not at all, reduced in other patients with similar reductions of albumin. Comparable abnormalities of serum albumin and SPI are seen in nephrosis without evidence of hypothyroidism and without any exact correlation with each other $(1,2)$. The cause of the low values of SPI in both conditions is unknown. In cirrhosis of the liver reduction in the serum albumin is associated with malnutrition (11). However, SPI is not abnormal in patients with marked malnutrition from various causes (12). In nephrosis and cirrhosis abnormalities in the proportions of the two components of the albumin fraction have been found by conducting the electrophoresis at $\mathrm{pH} 4.0$ (13). Such possible qualitative alterations in the serum albumin may affect the usual attachment of thyroxine to the proteins.
In contrast to the low values of SPI found in cirrhosis, high values are found early in the course of hepatitis. Many of the values are within the range usually associated with hyperthyroidism. However, although other objective determinations of thyroid function such as the measurement of the basal metabolic rate or the lipids of the serum are unreliable in acute hepatitis, none of these patients had clinical evidences of hyperthyroidism nor was the course suggestive of this disease. High values of SPI are found also in pregnancy (14), but the cause of the rise in the two conditions seems to be dissimilar inasmuch as the rise occurs in hepatitis only early in the course and is not related to the severity of the disease.

Only a small proportion of the iodine in urine resembles thyroxine either in euthyroid persons or hyperthyroid patients, whereas after the administration of thyroxine appreciable amounts are found in the feces $(15,16)$. Administered thyroxine soon leaves the plasma and appears in the liver, muscle and other tissues (17). In the liver not only does a steady degradation of the thyroxine occur, but also a proportion of the thyroxine is found in the bile and finally in the intestinal tract. When larger amounts of thyroxine are given, the proportion of thyroxine-like iodine found in the feces becomes high and, if the bile duct be ligated, the labeled thyroxine leaves the plasma much more slowly (15). That this degradation and excretion of thyroxine by the liver is important is suggested by a greater effectiveness of administered thyroxine when the liver is partially removed (18). Also thyroxine given intraperitoneally is less effective

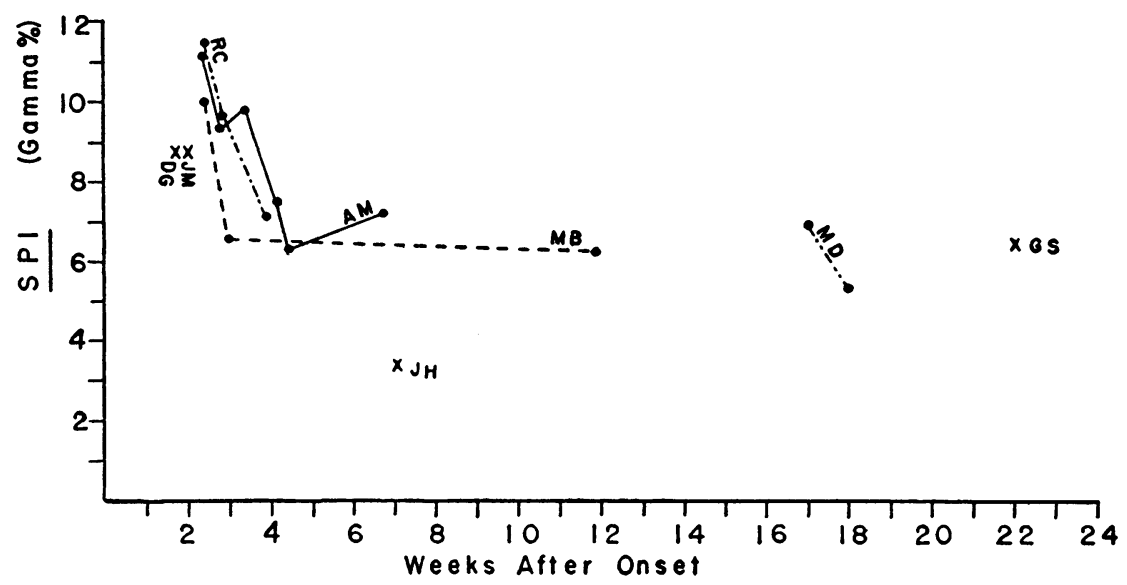

Fig. 1. SPI in Infectious Hepatitis 
than when given subcutaneously unless the bile duct is ligated (19).

In instances of biliary obstruction studied the excretory function of the liver is destroyed, but the liver cells may not all be sufficiently damaged to prevent the degradation to inorganic iodine of whatever thyroxine is presented. The inorganic iodide is excreted by the kidney and a normal SPI is found even though considerable derangement of hepatic function may be present. The normal SPI in obstructive jaundice indicates that the high SPI found early in hepatitis is not referable simply to retention.

In hepatitis, tests of liver function are found to be abnormal early in the course of the disease $(8,20,21)$. Biopsies of the liver taken during hepatitis and autopsy studies in fulminant cases show that widespread damage of the hepatic cells occurs soon after the onset (22-24). After a latent period, areas of regeneration appear and extend even though the patient may remain desperately or even fatally ill (24). The initial widespread damage caused by the disease may be sufficient to prevent the normal destruction of thyroxine by the liver. In addition, at this stage of the disease, the excretory function of the liver is destroyed. The kidney is able to excrete largely inorganic iodide and the organic iodinated compounds may, under these circumstances, increase in the serum. Later in the disease a sufficient number of liver cells may either recover or regenerate; a normal SPI is then found despite the continuance of other evidences of gross hepatic abnormalities.

\section{SUMMARY AND CONCLUSIONS}

1. SPI in five patients with obstructive jaundice was normal.

2. In cirrhosis SPI was either normal or low. When low, the serum albumin may also have been low but there was no consistent relationship between the two. The depressed SPI may be correlated with the severity of the disease but with no single test of hepatic function.

3. In hepatitis, elevation of SPI occurred early in the disease. After the first four weeks of illness no abnormal values were found. The possible significance of these alterations has been discussed.

\section{ACKNOWLEDGMENT}

Many of the determinations of bilirubin, alkaline phosphatase and bromsulphalein retention were performed in the laboratory of Dr. Gerald Klatskin who generously allowed the authors to use these results.

\section{REFERENCES}

1. Peters, J. P., and Man, E. B., The relation of albumin to precipitable iodine of serum. J. Clin. Invest., 1948, 27, 397.

2. Kydd, D. M., Man, E. B., and Peters, J. P., Concentration of precipitable iodine in the serum. J. Clin. Invest., 1950, 29, 1033.

3. Meyers, J., and Man, E. B., Artifactual values of serum precipitable iodine after clinical intramuscular injections of mercuhydrin. J. Lab. \& Clin. Med., 1951, 37, 867.

4. Danowski, T. S., Mateer, F., Weigand, F. P., Peters, J. H., and Greenman, J. H., Serum iodine fractions in subjects receiving potassium iodide in small doses. J. Clin. Endocrinol., 1950, 10, 532.

5. Milne, J., Serum protein fractionation: a comparison of sodium sulfate precipitation and electrophoresis. J. Biol. Chem., 1947, 169, 595.

6. Peters, J. P., and Man, E. B., The interrelations of serum lipids in normal persons. J. Clin. Invest., 1943, 22, 707.

7. Klatskin, G., and Yesner, R., Factors in the treatment of Laennec's cirrhosis. I. Clinical and histological changes observed during a control period of bedrest, alcohol withdrawal, and a mi:iiz: J. Clin. Invest., 1949, 28, i¿j.

8. Albrink, M. J., Man, F. B., and Peters, J. P., Serum lipids in inf.ctiuus hepatitis and obstructive jaundir: J. Clin. Invest., 1950, 29, 781.

r. Zassett, A. M., Coons, A. H., and Salter, W. T., Protein-bound iodine in blood. V. Naturally occurring iodine fractions and their chemical behavior. Am. J. M. Sc., 1941, 202, 516.

10. Taurog, A., and Chaikoff, I. L., The nature of the circulating thyroid hormone. J. Biol. Chem., 1948, 176, 639.

11. Man, E. B., Kartin, B. L., Durlacher, S. H., and Peters, J. P., The lipids of serum and liver in patients with hepatic diseases. J. Clin. Invest., 1945, 24, 623.

12. Man, E. B., Unpublished studies.

13. Luetscher, J. A., Jr., Electrophoretic analysis of plasma and urinary proteins. J. Clin. Invest., 1940, 19, 313.

14. Heinemann, M., Johnson, C. E., and Man, E. B., Serum precipitable iodine concentrations during pregnancy. J. Clin. Invest., 1948, 27, 91.

15. Gross, J., and Leblond, C. P., Distribution of a large dose of thyroxine labeled with radioiodine in the organs and tissues of the rat. J. Biol. Chem., 1947, 171, 309. 
16. Rall, J. E., Iodine compounds in the blood and urine of man. J. Clin. Endocrinol., 1950, 10, 996.

17. Gross, J., and Leblond, C. P., Metabolism of the thyroid hormone in the rat as shown by physiological doses of labeled thyroxine. J. Biol. Chem., 1950, 184, 489.

18. Kellaway, P. E., Hoff, H. E., and Leblond, C. P., The response to thyroxine after subtotal hepatectomy. Endocrinology, 1945, 36, 272.

19. Grad, B., and Leblond, C. P., Role of the liver in the thyroxine metabolism of the albino rat. Rev. Can. Biol., 1949, 8, 320.

20. Drill, V. A., Changes in liver function during experimentally induced human hepatitis. Yale J. Biol. \& Med., 1946, 18, 345.
21. Neefe, J. H., Stokes, J., and Gellis, S. S., Homologous serum hepatitis and infectious (epidemic) hepatitis; experimental study of immunity and cross immunity in volunteers. Am. J. M. Sc., 1945, 210, 561.

22. Dibble, J. H., McMichael, J., and Sherlock, S. P. V., Pathology of acute hepatitis; aspiration biopsy studies of epidemic, arsenotherapy and serum jaundice. Lancet, 1943, 2, 402.

23. Lucké, B., and Mallory, T. B., The fulminant form of epidemic hepatitis. Am. J. Path., 1946, 22, 867.

24. Mallory, T. B., The pathology of epidemic hepatitis. J. A. M. A., 1947, 134, 655. 